\title{
Compartimentação do relevo baseada em parâmetros morfométricos: uma análise da região do extremo oeste da Bahia
}

\section{Compartmentation of the relief based on morphometric parameters: an analysis of the region in the extreme West of Bahia}

\author{
André Barbosa Ribeiro Ferreira \\ Universidade Federal de São João del-Rei, Brasil \\ andreribeirogeo@gmail.com \\ Bráulio Magalhães Fonseca \\ Universidade Federal de Minas Gerais, Brasil \\ brauliomagalhaes@cart.igc.ufmg.br \\ Gabriel Pereira \\ Universidade Federal de São João del-Rei, Brasil \\ pereira@ufsj.edu.br
}

\begin{abstract}
Resumo
O sensoriamento remoto e as técnicas de geoprocessamento se tornaram tecnologias otimizadoras dos estudos ambientais e de diversos outros ramos da ciência. O estudo aqui apresentado possui o objetivo de identificar as áreas com maior susceptibilidade à dissecação e a partir disso possibilitar maiores análises, sobretudo no que se refere ao planejamento ambiental. Para o desenvolvimento da pesquisa utilizou-se o Índice Global de Dissecação do Relevo, proposta a partir da utilização e sobreposição de três parâmetros geomorfométricos. Os resultados obtidos apontaram que as áreas mais susceptíveis a dissecação encontram-se na faixa transicional entre o planalto da Serra Geral e a Depressão São Franciscana, principalmente onde ocorrem maiores concentrações de rugosidade.
\end{abstract}

Palavras-chave: Cartografia Geomorfológica; Geoprocessamento; Fragilidade natural.

\begin{abstract}
The remote sensing and geoprocessing techniques have become optimising technologies for environmental studies and various other fields of science. The study presented here aims to identify the areas with the most significant susceptibility to dissection and after that to enable further analysis, especially concerning environmental planning. For the development of the research was used the Global Relief Dissection Index, proposed from the use and overlapping of three geomorphometric parameters. The results showed that the areas most susceptible to dissection are in the transitional range between the Serra Geral plateau and the São Franciscan Depression, mainly where higher roughness concentrations occur
\end{abstract}

Keywords: Geomorphological Cartography; Geoprocessing; Natural fragility. 


\section{INTRODUÇÃO}

Na Geomorfologia, a cartografia é utilizada como uma técnica de representação gráfica e espacial que permite representar a gênese das formas do relevo e suas relações com a estrutura e os processos(AUGUSTIN et al., 2011; ROBAINA et al., 2010; RODRIGUES, 1998; GUSTAVSSON et al., 2006; COOKE et al., 1974;), ou seja, compartimentar o relevo desde as escalas regionais até as feições em escala de vertente (ROSS, 1992; GERRARD, 2008).

SegundoCasset (2005) Cartografia Geomorfológica é um instrumento importante na espacialização dos fatos geomorfológicos, pois viabiliza representar a gênese das formas do relevo e suas relações com a estrutura e processos. Para Otto e Smith (2013) a técnica promove um inventário da paisagem e dá subsídio para análises preliminares do uso da terra e para o gerenciamento de riscos geomorfológicos.

Para Simon e Lupinacci (2019), a cartografia geomorfológica constitui-se como ferramenta fundamental para a avaliação das fragilidades naturais e para a análise das mudanças provocadas por ação humana. Ela permite identificar as características do relevo e possibilita o planejamento do uso e ocupação das terras de modo a evitar terrenos de maior fragilidade ou ainda gerenciar tal fragilidade.

O advento do Sensoriamento Remoto e a manipulação de dados em SIG, além da criação de modelos matemáticos, favoreceram a simulação do comportamento sistêmico do ambiente e possibilitaram a análise de forma holística e interativa entre os elementos da paisagem, viabilizando a obtenção de dados morfométricos a partir de Modelos Digitais de Terreno e consequentemente a possibilidade de analisar o espaço temporal dos processos geomorfológicos(HARBOR, 1992; VAN DER BEEK; BRAUN, 1998; BOULTON; WHITTAKER, 2009; TUCKER; HANCOCK,2010; KUMAR, 2013).

Florenzano (2008) aponta que inúmeros métodos, técnicas e equipamentos permitem analisar as formas e diferentes processos do relevo, além de combinar informações extraídas de dados de sensoriamento remoto com observações de campo, integrando-as aos objetos de estudo da geomorfologia, como a morfologia, morfogênese e morfométrica.

Dentre esses objetos de estudo a morfometria vem se destacando por ser o aspecto mensurável e quantitativo, sendo utilizada não só em análises geomorfológicas, mas também geológicas, pedológicas e agronômicas (FLORENZANO, 2008; HARTEMINK, 2015; SAMPAIO e AUGUSTIN, 2008; SAMPAIO; AUGUSTIN, 2014; HARTWIG; RICCOMINI, 2010; FONSECA, 2010; FONSECA; AUGUSTIN, 2011; LIMA et al., 2011; CAMOLEZI et al., 2012).

As análises morfológicas, apesar de serem o ponto de partida do entendimento do relevo, segundo Sampaio e Agostini (2014),podem ser subjetivas e muito dependentes do grau de 
conhecimento e olhar do pesquisador, entretanto, a incorporação dos Modelos Numéricos de Terreno nessas análises possibilita a melhoria do mapeamento geomorfológico a partir da extração de parâmetros numéricos do relevo que podem ser incorporados a metodologias de análise já existentes ou serem variáveis integrantes de novas propostas metodológicas, como o Índice Global de Dissecação do Relevo (IGDR), proposto por Souza et al.. (2017).

O IGDR relaciona-se diretamente com a Fragilidade Potencial Natural discutida por Sprol e Ross (2004), envolvendo outros índices geomorfológicos consolidados na literatura, como a Densidade de Drenagem, a Concentração de Rugosidade e Índice de Hack.

A metodologia foi aplicada para a região do extremo oeste baiano, área com aproximadamente $88,6 \mathrm{~km}^{2}$ localizada entre as coordenadas $46,9^{\circ} / 43,8^{\circ}$ de longitude oeste e $10,13^{\circ} / 15,32^{\circ}$ de latitude sule que no decorrer das últimas décadas vem passando por uma intensificação do uso da terra. Desse modo a aplicação do IDGR surge com o intuito de compor o planejamento territorial, identificando as áreas naturalmente instáveis e mais susceptíveis à dissecação.

\section{METODOLOGIA}

\section{1 Índice Global de Dissecação do Relevo (IGDR)}

O relevo e suas formas têm influência direta sobre os processos erosivos, já que possuem o poder de convergir ou divergir os fluxos hídricos, reelaborando todo um sistema. Segundo Devicari (2009), essa influência é resultado da morfologia, sua forma, ou seja, são informações, análises que mesmo resultantes de observações sistemáticas são apenas qualitativas e, conforme Sampaio e Augustin (2014).

Desse modo, para eliminar tais subjetividades recorre-se a parâmetros morfométricos, quantitativos das formas do relevo, que aliados a modelos digitais de elevação possibilitam calcular uma gama de processos, dentre eles a dissecação do relevo.

Para a análise do processo de dissecação do relevo na Região Oeste do estado da Bahia optou-se pelo método proposto por Souza et al., (2017), o Índice Global de Dissecação do Relevo (IGDR), baseado em três outras análises morfométricas (Figura 1): o Índice de Concentração da Rugosidade (ICR), o Índice de Hack e a Densidade de Drenagem, descritos separadamente abaixo: 


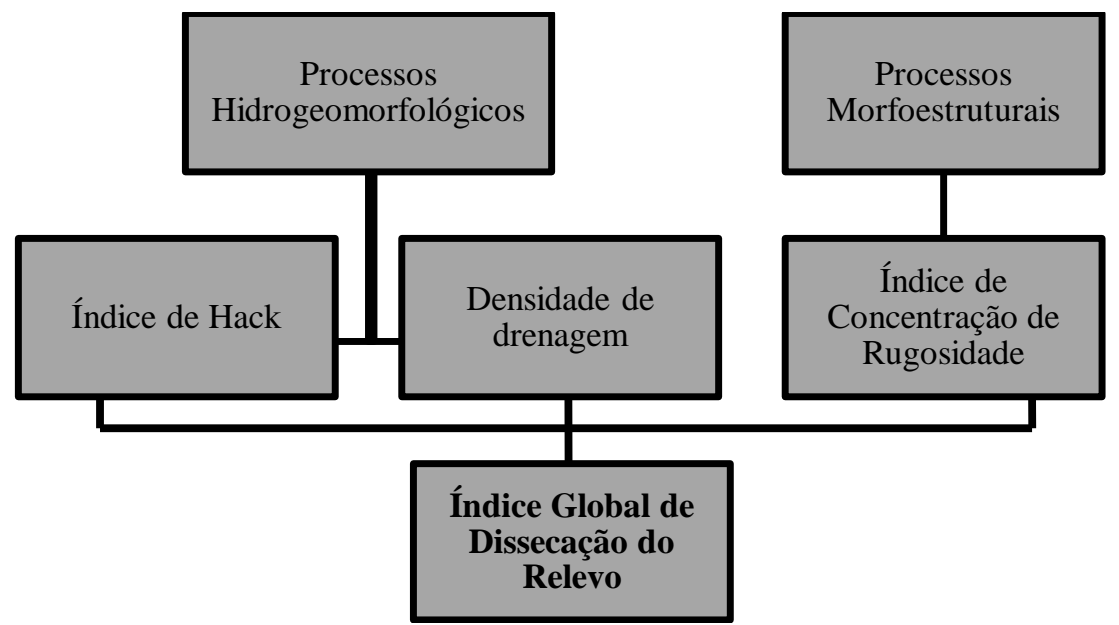

Figura 1 - Fluxograma de obtenção do IGDR.

\section{2 Índice de Concentração da Rugosidade (ICR)}

Consiste em uma técnica metodológica(Figura 2) proposta por Sampaio e Augustin (2014) com o intuito de subsidiar o mapeamento e a quantificação de dissecação a partir de informações cartográficas e geomorfológicas. De acordo com Souza et al., (2017), o ICR é basicamente uma delimitação das unidades de relevo que leva em consideração padrões de rugosidade presentes numa região.
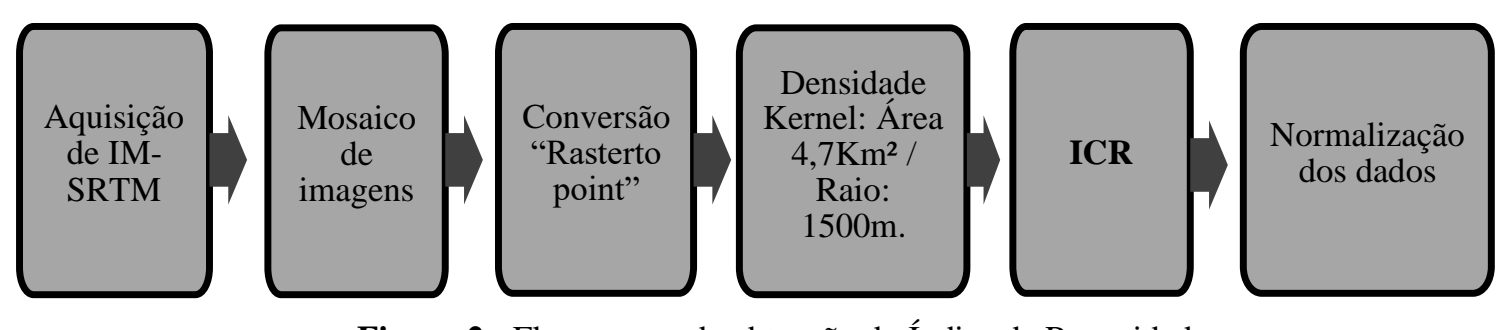

Figura 2 - Fluxograma da obtenção do Índice de Rugosidade.

Sampaio e Augustin (2014) consideram que o índice se enquadra no grupo das análises tridimensionais que possibilitam a aquisição de valores para representar unidades homogêneas de relevo visando à incorporação destes quantitativos em modelos matemáticos ou estatísticos. Para Pereira Neto e Fernandes (2012), o índice vem sendo bastante empregado em diversas pesquisas, ele oferece, pois, importantes bases para o entendimento e identificação de áreas potencialmente instáveis expostas aos diferentes processos erosivos e de degradação, sendo um subsídio essencial no controle e minimização dos mesmos.

O ICR foi aplicado para a Região Oeste do estado da Bahia a partir da utilização de imagens do satélite AsterGdem, que, após serem importadas para o aplicativo ArcMap, foram convertidos em malha de pontos com valores correspondentes aos pixels originais, permitindo a aplicação do estimulador de Densidade por Kernel, um método estatístico de estimativa de curvas de densidades traçadas a partir de uma vizinhança circular ao redor de cada ponto amostrado em função de um 
raio de influência estipulado, na qual quanto maior o raio maior a generalização da informação (SOUZA, 2014). O raio traçado para a análise foi de $1500 \mathrm{~m}$, o que abrange uma área de aproximadamente $4,7 \mathrm{~km}^{2}$.

O resultado do processamento foi agrupado em 5 classes de intervalos utilizando o método de quebras naturais (Natural Breaks) e em seguida normalizados por operação álgebra (Equação 1) entre 0 e 1 com objetivo de padronizar os valores obtidos e a possibilitar comparações entre diferentes estudos, independente da resolução espacial do Modelo Digital de Elevação de origem:

$$
f(x)=(X-\operatorname{Min}) * 1 /(\operatorname{Max}-\operatorname{Min} \text {. })
$$

onde $X$ corresponde ao raster resultante dividido pela diferença de seus valores máximo e mínimo.

\section{3 Índice de Hack ou Relação Declividade Extensão (RDE)}

Proposto por Hack (1973), o índice estabelece uma relação entre a declividade e a extensão das redes de drenagem. Cremon (2013) considera que o método é um parâmetro quantitativo significante, pois está relacionado à potência do canal (streampower) para transportar material de dada granulometria e às características do canal com a resistência de fluxos, proporcionando comparações de diferentes cursos fluviais ou trechos e verificando anomalias morfoestruturais.

Monteiro et al.. (2010)considera que a proposta determina se um canal encontra-se em equilíbrio geomorfológico baseado na relação entre a encosta do rio e a extensão da área da bacia. A técnica permite detectar alterações nos cursos de água, decorrente de mudanças no substrato geológico, aporte de carga ou tectonismo, ou simplesmente a relação declive e extensão do canal (SOUZA et al., 2011) (Figura 3).

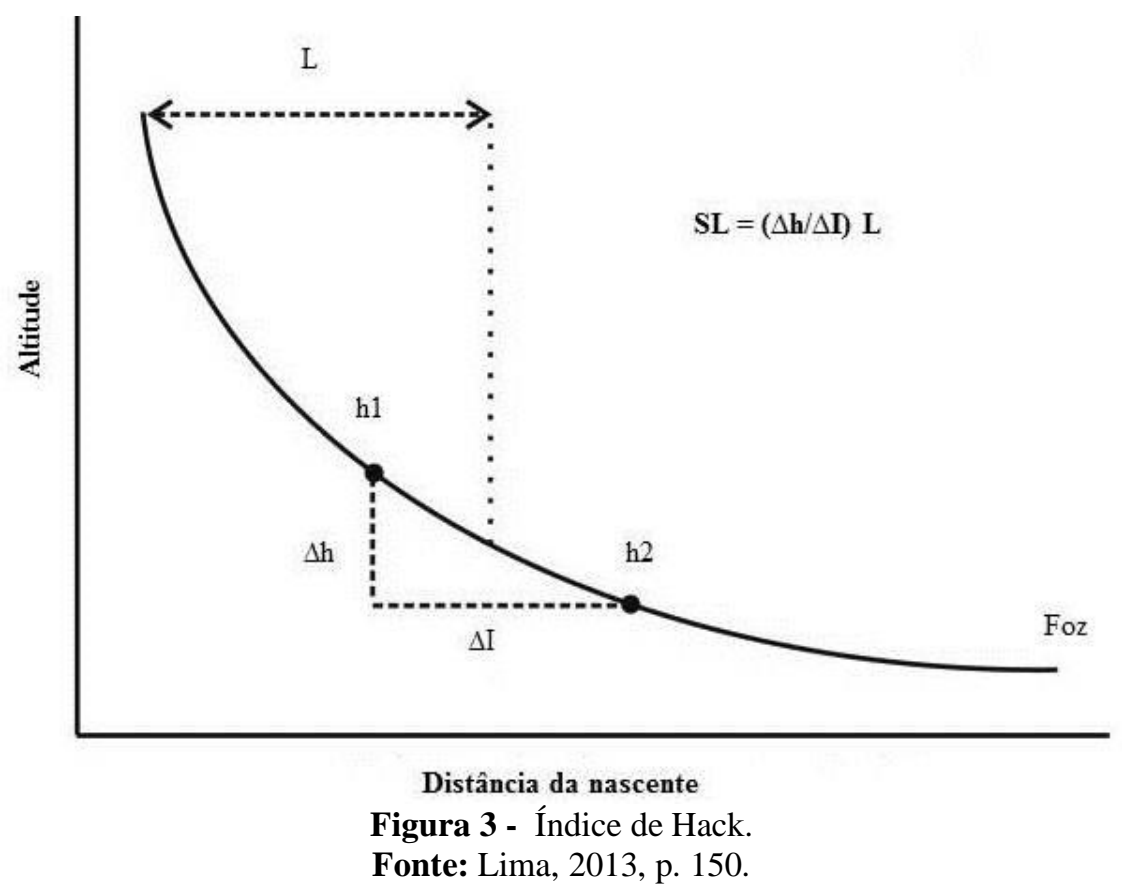


Para essa pesquisa, o Índice de Hack foi utilizado com o intuito de indicar o vigor energético dos canais de drenagem e relacionar essa variável ao processo de dissecação e evolução do relevo (SOUZA, 2017). O índice pode ser calculado conforme mostra a figura acima (Figura 3), onde $\mathrm{L}$ corresponde ao comprimento da drenagem, $\Delta \mathrm{h}$ a diferença de altitude entre duas isoípsas $\mathrm{e}$ $\Delta \mathrm{I}$ a projeção horizontal do comprimento do segmento de drenagem entre duas isoípsas.

A obtenção do $\Delta$ Hdos segmentos hierarquizados da rede hidrográfica foi realizada por um processamento MDE (imagem AsterGdem) de estatística zonal utilizando o aplicativo ArcMap com a extensão Knickpoint do Arc Toolbox em escala de 1:250.000 e equidistância de 100 metros. O processamento gerou um conjunto de células de umraster com o mesmo valor. Os valores de $\Delta \mathrm{L}$ foram calculados em metros e, em seguida, normalizados por operação álgebra (Equação 1) entre 0 e 1 com objetivo de padronizar os valores obtidos e a possibilitar comparações entre diferentes estudos(Figura 4).
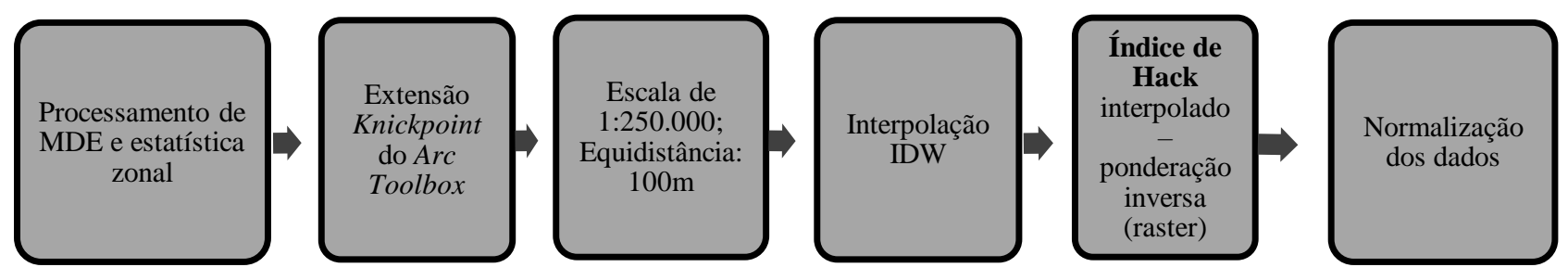

Figura 4 - Fluxograma da obtenção do Índice de Hack.

\subsection{Densidade de Drenagem}

A Densidade de Drenagem indica a eficiência dos canais na bacia e é definida pela relação entre o comprimento total dos cursos d'água (L) e a área da drenagem (A), de forma que: $\mathrm{Dd}=$ L/A.Segundo Porto et al., (1999), quanto maior a Densidade de Drenagem da bacia, mais rapidamente a água do escoamento superficial chegará à saída da bacia.

Hiruma e Ponçano (1994) afirmam que Densidade de Drenagem é reconhecida como um dos mais importantes parâmetros da análise morfométrica de bacias hidrográficas e foi definida inicialmente por Horton (1945) como o comprimento médio de rios de uma bacia hidrográfica por unidade de área. Lima (2008) considera que o índice é reflexo da geologia, topografia, do solo e da vegetação da bacia hidrográfica, e está relacionado com o tempo gasto para a saída do escoamento superficial da bacia. O clima atua tanto diretamente quanto indiretamente na densidade de drenagem, considerando que está ligado à perenidade dos canais e vegetação. As características físicas, a rocha e o solo também desempenham papel fundamental, pois determinam a maior ou menor resistência à erosão. 
A análise da Densidade de Drenagens na área de estudo considerou o método utilizado por Souza et al., (2017), em que a densidade de drenagem representou um indicador de zonas anisotrópicas do relevo, onde ocorrem processos erosivos mais intensos e com estreita correlação espacial com a dissecação.A aquisição da densidade de drenagem se deu a partir da utilização do aplicativo ArcMap e do Estimulador de Densidade por Kernelem três atributos: a ordem dos canais, o comprimento e a quantidade. $\mathrm{O}$ raio de busca e análise foi proporcional à área, aplicando-se um raio de 1500 metros após a observação de uma alta densidade de drenagens no local. Assim como no ICR e Índice de Hack, a Densidade de Drenagem foi normalizada por operação álgebra (Equação 1) entre 0 e 1 com objetivo de padronizar os valores obtidos.

O resultado dessas três análises proporcionaram a aplicação do IGDR a partir do processo de álgebra de mapas com os rasters de ICR, Índice de Hack e Densidade de Drenagem que, segundo Souza (2017, p.5520) correspondem à atuação dos processos hidrogeomorfológicos e morfoesculturais nas formas existentes do relevo e funciona como uma indicação do potencial dos processos erosivos na paisagem.

As normalizações entre 0 e 1 efetuadas nas etapas anteriores permitiram a interação das variáveis na seguinte fórmula (equação 2):

$$
\mathrm{IGDR}=(\mathrm{ICR} \text { Global } \times 0,33)+(\mathrm{IH} \times 0,33)+(\text { Den. Dre } \times 0,33)
$$

Souza (2017) propõe a normalização de modo que os três índices possuam o mesmo peso na expressão, não havendo uma influência maior de algum índice na matriz resultante.

\section{RESULTADOS}

\subsection{Hipsometria}

A análise hipsométrica constitui uma importante ferramenta de observação para o entendimento da topografia e das dinâmicas geomorfológicas, no entanto, segundo Souza (2014) o mapa hipsométrico pode omitir algumas formas e compartimentos topográficos, escondendo as variações existentes no interior de estruturas geológicas.

O mapa (Figura 5), portanto, demonstra que as cotas altimétricas mais elevadas estão situadas na porção oeste da área de estudo, margeando a encosta do denominado Planalto Geral, com altitudes entre $826 \mathrm{~m}$ e $1079 \mathrm{~m}$ que tendem a diminuir à medida que se aproxima da região central e leste, às margens da Depressão São Franciscana. São nas faixas central e leste, onde as altitudes variam entre 630 e 730m, que identificam-se as áreas mais declivosas e escavadas por canais de drenagem. 


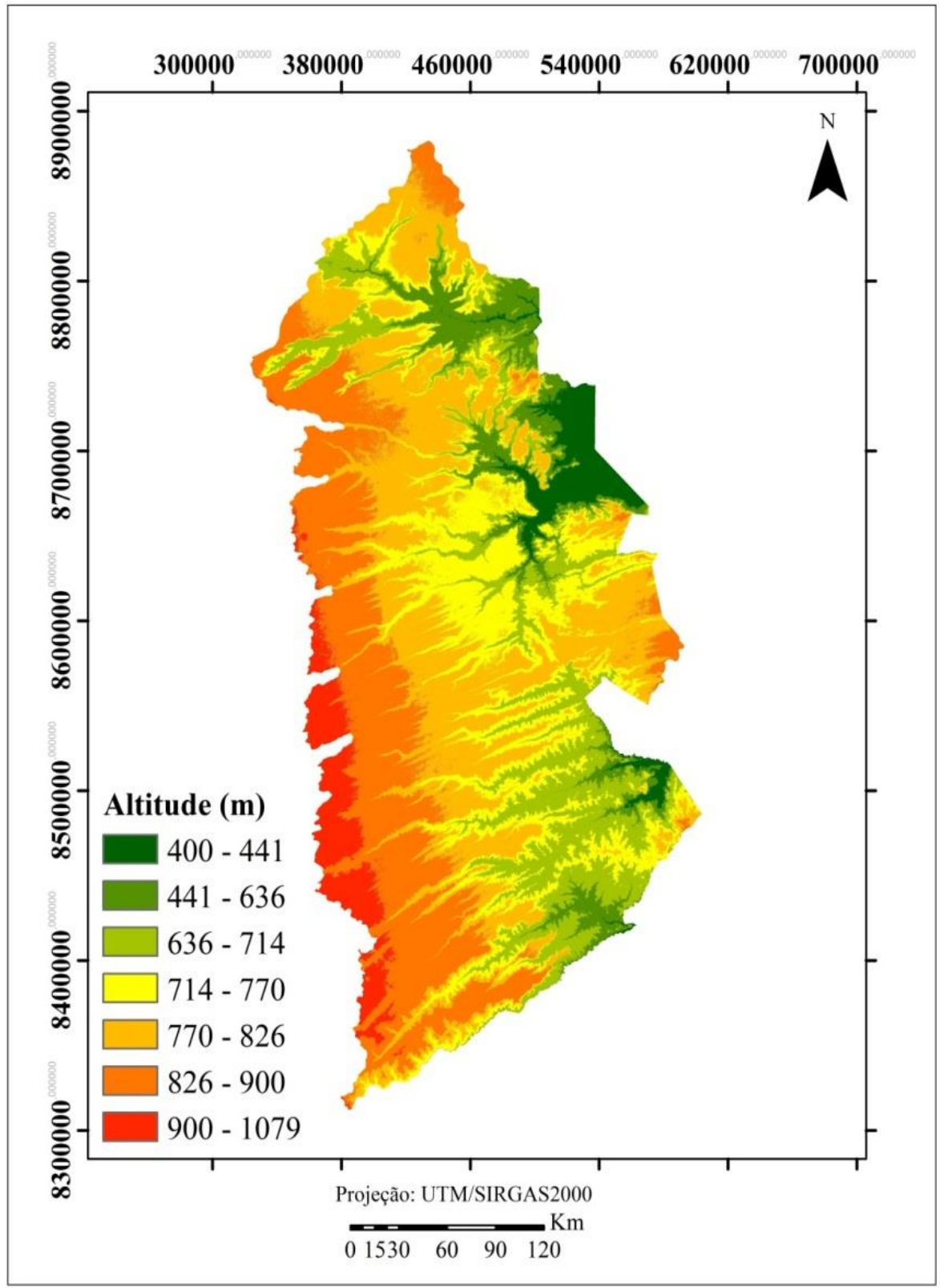

Figura 5 - Mapa Hipsométrico.

\section{2 Índice de Concentração de Rugosidade (ICR)}

O ICR permite, a partir da espacialização da densidade dos valores de declividade, discriminar o relevo de acordo com o grau de dissecação. Segundo Souza (2014) a técnica auxilia nas pesquisas geomorfológicas tomando o relevo como uma variável numérica e menos subjetiva, permitindo uma leitura tridimensional dos fatos geomorfológicos a partir da classificação morfométrica.

A aplicação do índice para a região oeste da Bahia resultou basicamente em duas áreas homogêneas e uma de transição, onde os baixos valores de rugosidade são representados pela cor verde, enquanto os altos coeficientes estão representados pela cor vermelha e as faixas de transição, ou seja, médias rugosidades, em amarelo (Figura 6). 


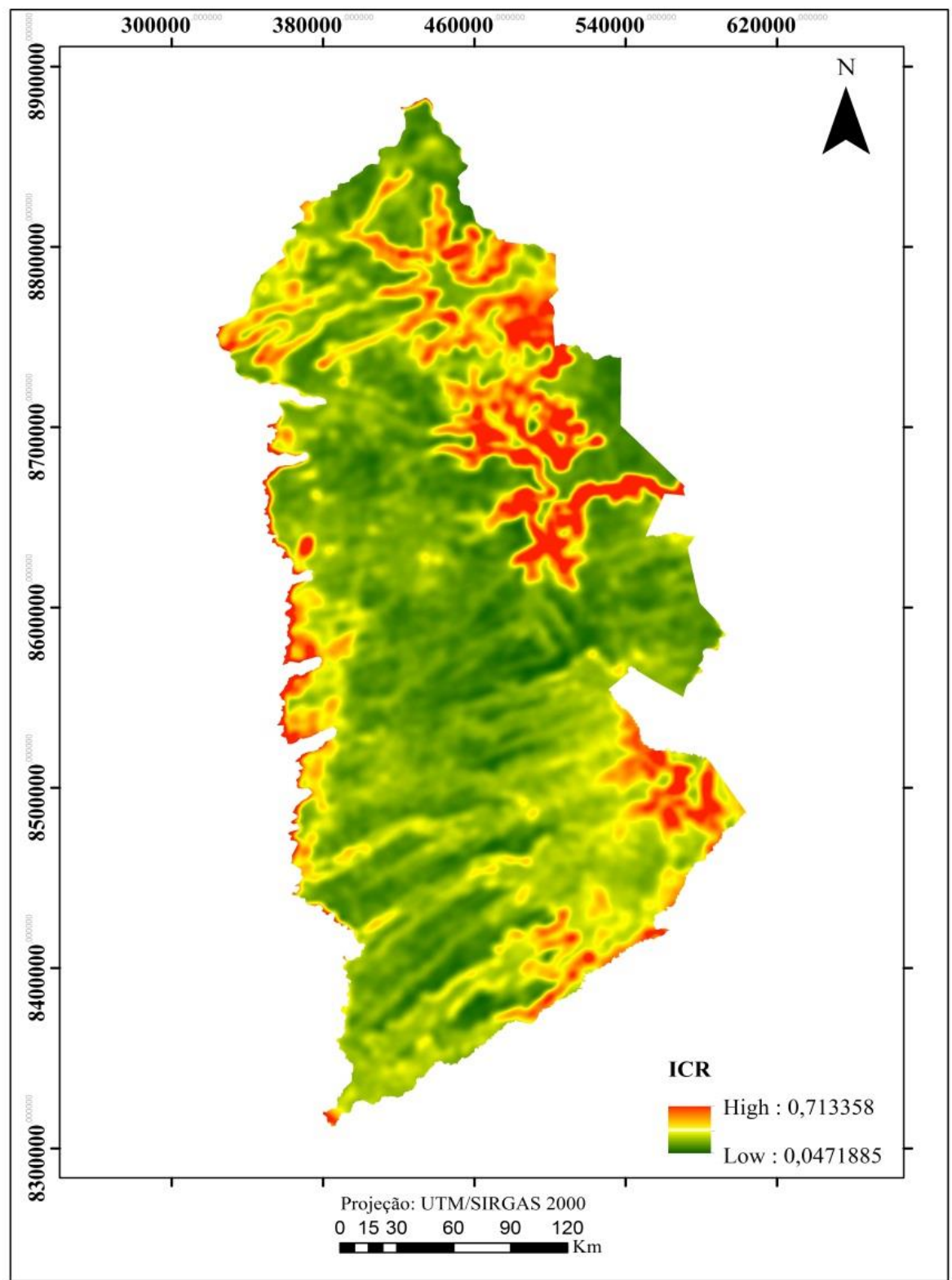

Figura 6 - Mapa do Índice de Concentração de Rugosidade (ICR).

Os maiores valores de rugosidade concentram-se, sobretudo, nas áreas mais declivosas, nas altitudes mais elevadas e nas transições entre as médias e baixas altitudes, coincidindo em diversos pontos com a própria geometria do mapa hipsométrico e de declividade, acompanhando linhas e feições resultantes do processo de incisão de drenagens em densidades significativas e rupturas de relevo. Como afirma Pereira Neto e Fernandes (2012, p.1406), "pode-se observar que o índice de rugosidade topográfica encontra-se intimamente atrelada à concentração dos diferentes índices de declividade e amplitude altimétrica.".

Segundo Gonçalves (2016) a avaliação do coeficiente de rugosidade significa estimar a resistência ao escoamento, ou seja, a fragilidade natural do ambiente (ROSS, 1994). Assim, considerando-se que a erosão está intrinsecamente ligada à topografia do terreno, dentre outros fatores, as áreas com maiores concentrações de rugosidade estão mais susceptíveis ao processo de dissecação, como aponta o mapa de ICR (Figura 6). 


\section{3 Índice de Hack (IH) ou Relação Declividade Extensão (RDE)}

Dentro das inúmeras abordagens de análise de perfis longitudinais, uma das mais utilizadas foi desenvolvida por Hack (CREMON, 2013) e é um indicador preciso de mudanças na declividade do canal fluvial e de onde ele possui maior energia, podendo estar associado às desembocaduras de tributários, às diferentes resistências à erosão hidráulica do substrato rochoso e/ou à neotectônica (BARBOSA, 2013).

A representação dos valores resultantes da aplicação do Índice de Hack para o oeste da Bahia (Figura 7) mantém o mesmo padrão do Índice de Rugosidade apresentado acima (Figura 6). A cor vermelha representa pontos de maior energia, amarelo alaranjado áreas de transição e a cor verde menor energia.

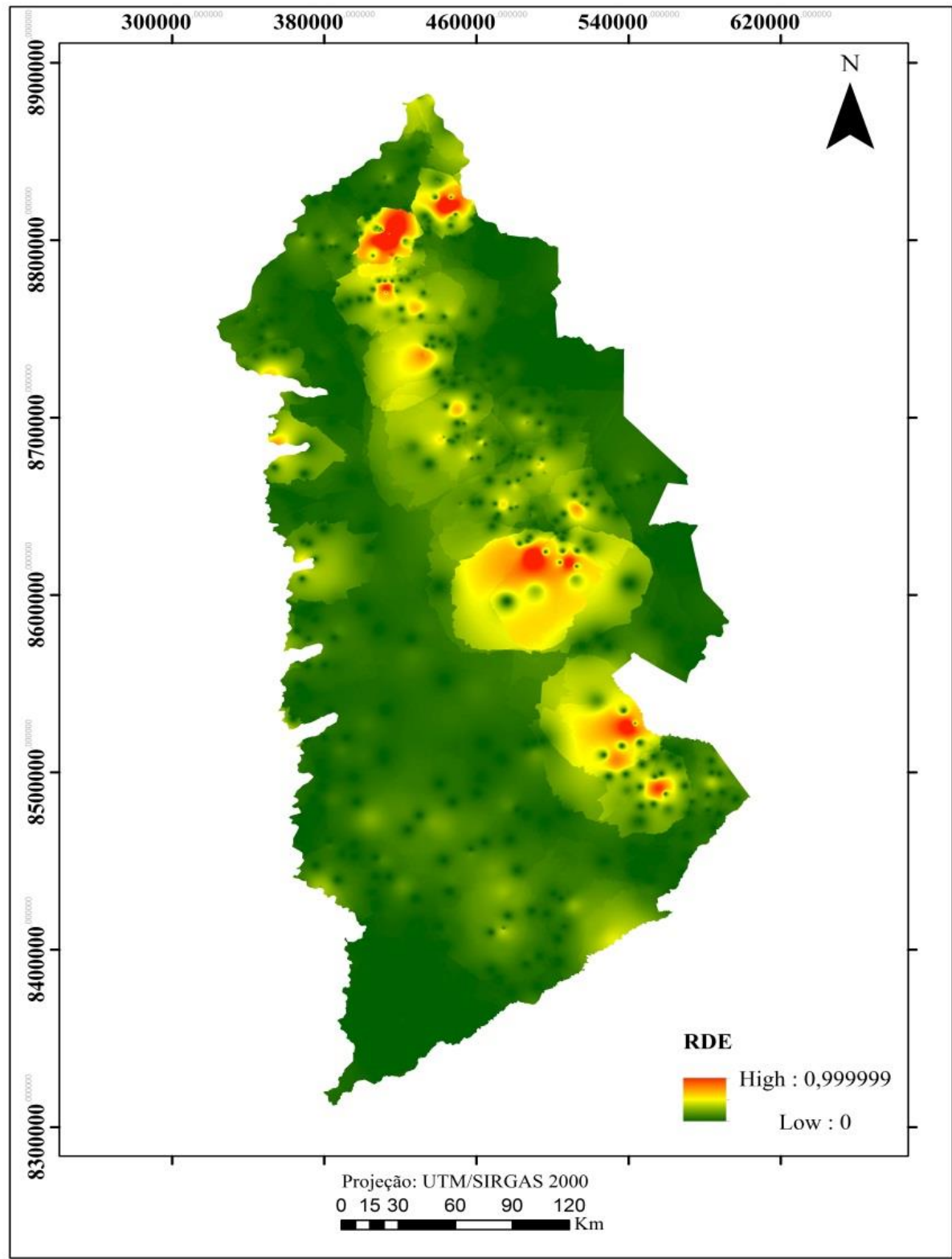

Figura 7 - Mapa de Índice de Hack (IH) ou Relação Declividade Extensão (RDE). 
O processamento resultou em um alinhamento de áreas de maior vigor energético, ou anomalias, na região centro leste, em altitudes baixas e médias, entre $400 \mathrm{~m}$ e $800 \mathrm{~m}$. As declividades nessas áreas podem ser classificadas como altas e médias, contendo altos índices de rugosidade.

Nota-se que a partir desse alinhamento de áreas com maior vigor energético ocorre uma pequena alteração na direção de alguns canais de leste para nordeste. Além disso, no "hot spot", central ocorre uma anomalia em cotovelo no padrão do canal, o que pode ser um indício de uma neotectônica (JANONI et al., 2016), principalmente quando se observa também a mudança dos padrões de drenagem de retilíneos e paralelos para subparalelos e dendríticos a partir dessas alterações na direção dos canais.

\subsection{Densidade de Drenagem}

Por representar a quantidade de canais em uma determinada área e o grau de dissecação dos mesmos, a análise da densidade de drenagem pode ser uma importante ferramenta para os estudos morfométricos, sobretudo em nível de bacia hidrográfica. Segundo Ramos et al. (2014), a densidade de drenagem reflete o comportamento do escoamento nos canais, permitindo avaliar os níveis de equilíbrio da paisagem através do fluxoatual e também identificar fluxos passados.

O mapa de Densidade de Drenagem da região oeste da Bahia (Figura 8), seguindo o mesmo padrão de representação do IDR e RDE, possui um potencial de dissecação significativo, especialmente nos canais de ordem mais elevada que cortam a região no sentido W/E e SW/NE.

Infere-se que a concentração dos maiores potenciais de dissecação nesses canais de ordem mais elevada possua relação direta com o aumento do fluxo de energia a partir de canais tributários, principalmente quando se observa os pontos onde os canais afluentes desembocam no rio principal, provavelmente tendo seu vigor energético aumentado diante de possíveis rupturas que constituem o nível de base local.

De modo geral, apesar das diferenças altimétricas e de declividade, pode se considerar que a densidade de drenagem na área de estudo não apresenta hots-spots, ou seja, apesar da existência de diversos pontos mais susceptíveis a dissecação, estes estão distribuídos de forma equilibrada, não havendo concentrações. Pode-se atribuir isso à homogeneidade do embasamento rochoso, composto basicamente de arenitos do Grupo Urucuia, exceto nas áreas mais rebaixadas do extremo leste, na qual afloram sedimentos de areia e silte, já nas proximidades da Depressão São Franciscana. 


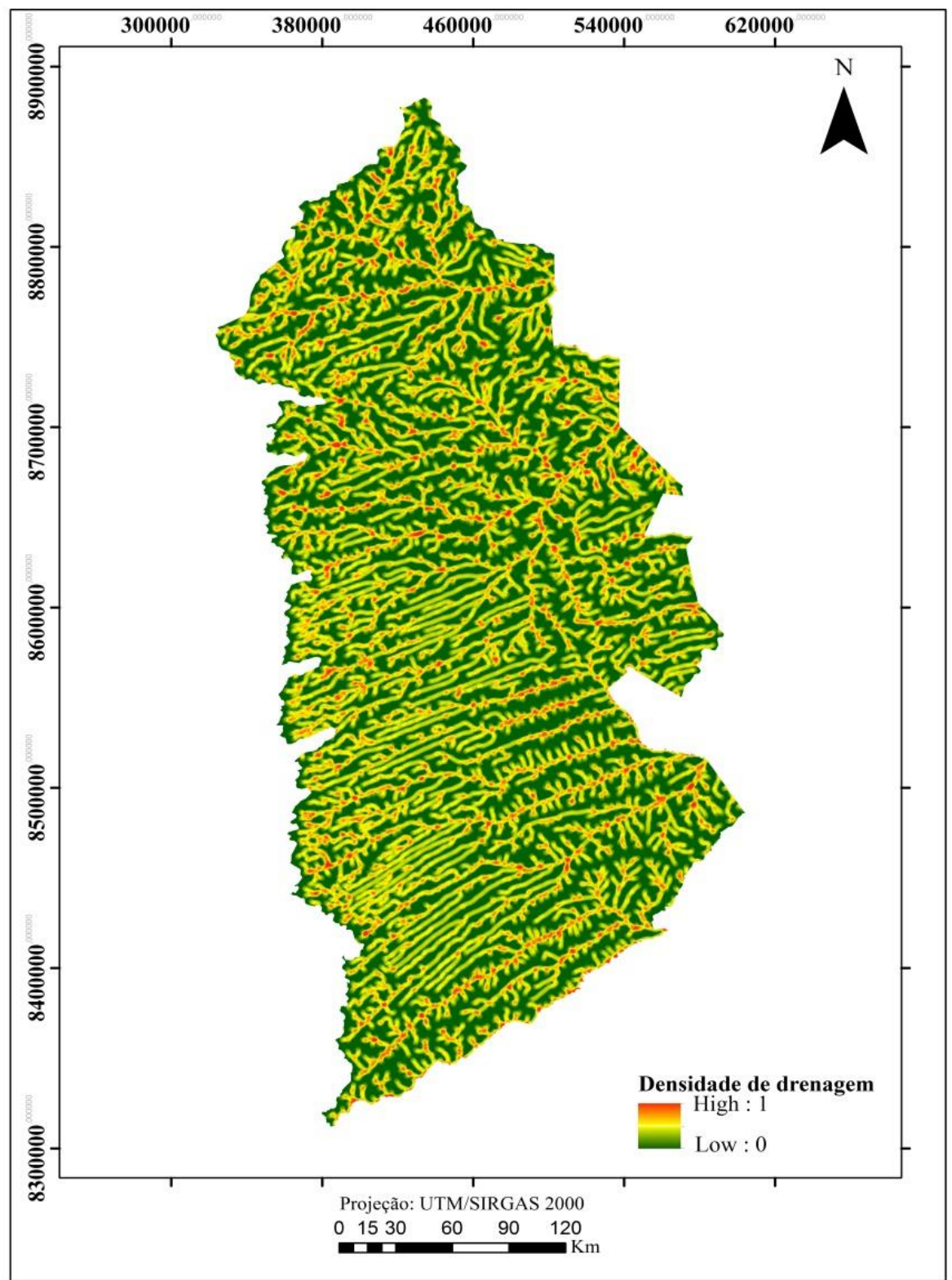

Figura 8 - Mapa de Densidade de Drenagem.

\section{5 Índice Global de Dissecação do Relevo - IGDR}

O Índice Global de Dissecação do Relevo corresponde a uma junção dos índices de Hack, Rugosidade e de Densidade de Drenagem. Segundo Souza (2014), o IGDR não considera apenas as formas do relevo, mas também sua dinâmica hidrogeomorfológica e potencial de modelagem das feições, permitindo avaliar a influência dos agentes modeladores e determinar as áreas de maior instabilidade, ou seja, áreas mais susceptíveis à dissecação.

Conforme mostra o mapa acima (Figura 9), as áreas de maior instabilidade geomorfológica, em vermelho, encontram-se em parte da faixa centro-oriental do planalto, entre as baixas e médias altitudes, sobretudo próximas às faixas de maior potencial energético, segundo o Índice de Hack. Além disso, ocorre também no extremo leste-nordeste da imagem, faixas com altitudes menos significativas, transicionais e de declividade mais acentuada, grande concentração 
desses pontos de susceptibilidade, correspondendo geometricamente às áreas de maior concentração de rugosidade, onde, provavelmente, o escoamento também adquire maior energia, modelando a paisagem.

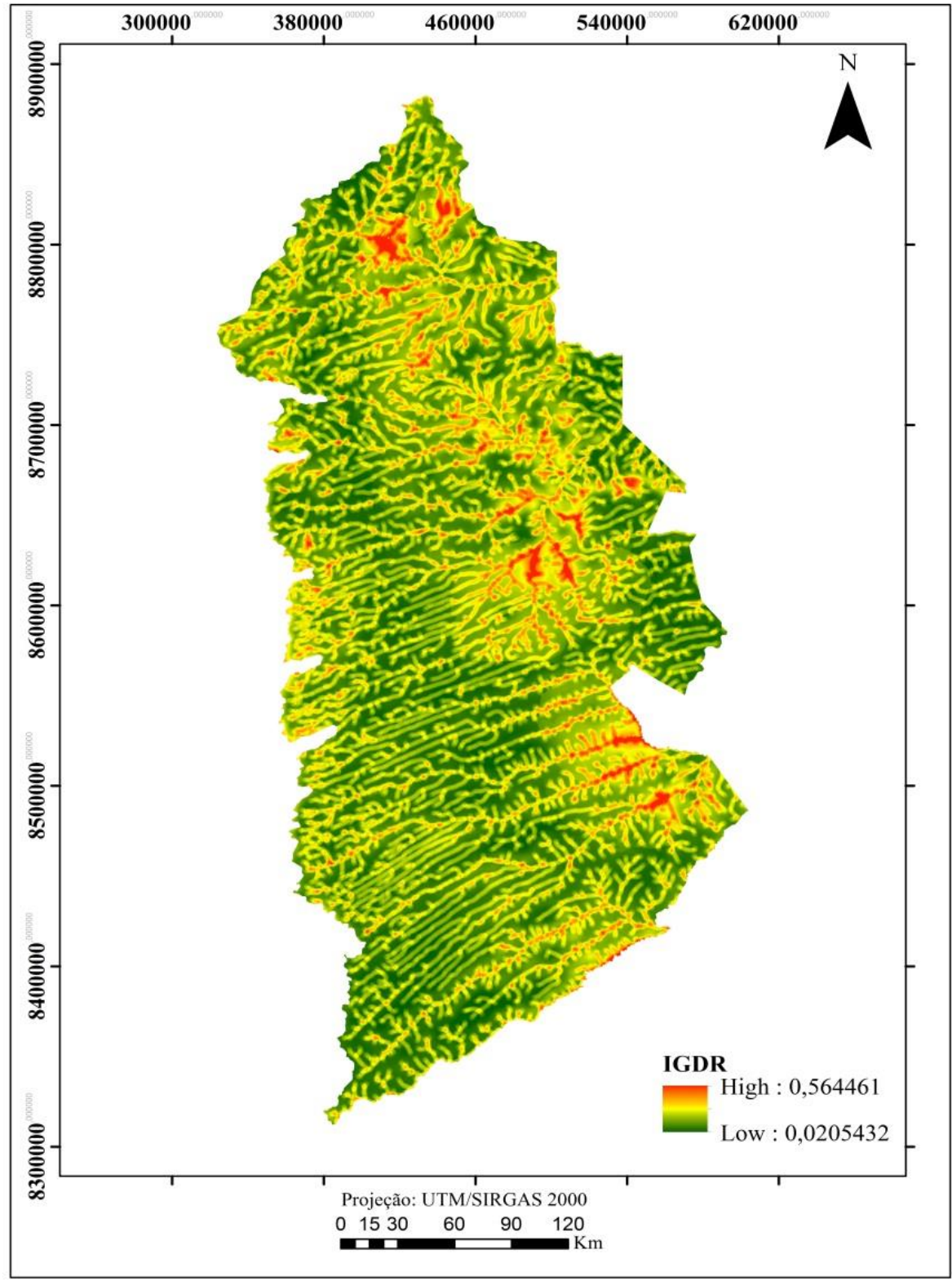

Figura 9 - Mapa do Índice Global de Dissecação do Relevo - IGDR.

As áreas com menor susceptibilidade à dissecação estão entre os limites de canais de drenagem, correspondendo ao interflúvio dessas sub-bacias, apresentando maior estabilidade a partir do momento em que direciona os fluxos para um canal em sua proximidade, tornando-o mais energético em relação ao potencial de dissecação e transporte.

De modo geral pode-se afirmar que as principais áreas de instabilidade natural correspondem também a áreas de grande interferência antrópica, como por exemplo, nos municípios de Formosa do Rio Preto e São Desiderio. Essa união entre a interferência antrópica e a 
instabilidade natural pode intensificar a ação dos agentes modeladores da paisagem e consequentemente o processo de dissecação.

\section{CONSIDERAÇÕES FINAIS}

Os resultados obtidos a partir da análise topográfica confirmam relevante susceptibilidade a dissecação na área de estudo, sobretudo na faixa intermediária, entre as baixas e altas altitudes e rupturas de relevo marcadas por declividades elevadas e maior concentração de rugosidades, direcionamento e concentração das linhas de drenagem. Essa faixa transicional marca a borda oriental do planalto da Serra Geral em direção a Depressão São Franciscana.

Em conjunto a essas características naturais vem a ação antrópica como fator intensificador do potencial de dissecação. A crescente retirada da vegetação natural, aumento populacional e das atividades agrícolas nas últimas décadas impulsionam o processo natural, pois são ações executadas na grande maioria das vezes sem os devidos estudos prévios e planejamento.

Desse modo os resultados gerados a partir da aplicação do IGDR favorecem e indicam a necessidade de um planejamento ambiental para a área de estudo, considerando principalmente o vertiginoso crescimento do uso, ocupação e execução de atividades desenvolvidas na região em análise do decorrer das últimas décadas.

As análises geomorfológicas foram apresentadas em nível regional, sem aprofundamento, mesmo porque não era a proposta deste estudo, cujo enfoque foi gerar compartimentações a partir de dados quantitativos, sem análises subjetivas. Apesar dessas considerações e dos índices serem embasados em dados sólidos e coesos, a análise não exclui a necessidade de visitas a campo para validação.

\section{REFERÊNCIAS}

BARBOSA, T. S. Aplicação de índices geomórficos para análise morfológica e neotectônica da bacia do rio Marés - PB. 2013. 65 f. (Monografia) - Curso de Geografia, Universidade Federal da Paraíba, João Pessoa, 2013.

CASSETI, V. Cartografia Geomorfológica, 2005. Livro Digital. Disponível em: <http://www.funape.org.br/geomorfologia/>. Acesso em: 02 fev. 2017.

CREMON, E. H. Espacialização da anomalia do índice de Hack como suporte a estudos morfoestruturais.2013. 26 f. Monografia (Especialização) - Curso de Programa de Pós-Graduação em Sensoriamento Remoto, Instituto Nacional de Pesquisas Espaciais, São José dos Campos, 2013.

DEVICARI, L. F. O modelado de dissecação do relevo como fator topográfico na Equação Universal de Perda de Solo aplicado ao município de São Pedro do Sul - RS. 2009. 124 f. 
Dissertação (Mestrado) - Curso de Programa de Pós-Graduação em Geografia e Geociências, Universidade Federal de Santa Maria, Santa Maria, 2009.

FLORENZANO, T. G. Geomorfologia: conceitos e tecnologias atuais. 1. ed. São Paulo: Oficina de Textos, 2008. 320p.

GONÇALVES, J. A. V. Caracterização do coeficiente de rugosidade e seu efeito no escoamento em Canais Naturais. Simulação e Modelação (à escala) no laboratório de hidráulica. Aplicação às ribeiras do Funchal. 2016. 168 f. Dissertação (Mestrado) - Curso de Engenharia Civil, Centro de Competências de Ciências Exatas e da Engenharia, Universidade da Madeira, Portugal, 2016.

HACK, J. T. Stream-profile analysis and stream-gradient index. Journal of Research of the United States Geological Survey, v. 1, n. 4, p. 421-429, 1973.

HARTEMINK, A. E. New tools for pedologists: Digital soil morphometrics. Soil Horizons, v. 56, n. 2, p. $1-2,2015$

HIRUMA, S. T.; PONÇANO, W. L. Densidade de drenagem e sua relação com fatores geomorfopedológicos na área do alto Rio Pardo, SP e MG. Revista do Instituto Geológico, São Paulo, v. 15, n. 1, p. 49-57, 1994.

JANONI, C.R; CASTRO, M.S.S, SANTOS, G.B.;JANONI, A.S.R; SOUZA, D.P.C. Neotectônica nas Coberturas Sedimentares do Cráton do São Francisco no oeste da Bahia. Revista de Geologia, Fortaleza, v. 29, n. 1. p. 93-111, 2016.

LIMA, A. G. Índice de gradiente de canal: significados e diretrizes para aplicação. Geosul, v. 28, n. 56, p. 147-162, 2013.

MONTEIRO, K. A.; MISSURA, R.; CORREA, A. C. B. Application of the Hack index - or stream length-gradient index (sl index) - to the Tracunhaém river watershed, Pernambuco, Brazil. Geociências - Unesp, São Paulo, v. 29, n. 4, p. 533-539, 2010.

OTTO, J. C.; SMITH, M. J. Geomorphological mapping.British Society for Geomorphology Geomorphological Techniques, v. 2, n. 6, p. 1-10, 2013.

PEREIRA NETO, M. C.; FERNANDES, E. Concentração de rugosidade topográfica: subsídios ao estudo de fragilidade potencial da bacia hidrográfica do Rio Seridó. Revista Geonorte, Natal, v. 2, n. 4, p. 1396-1405, 2012.

RAMOS, D. A. M. C.; TAVARES, R.; SILVA, D. G.; CORREA, A. C. B. Densidade de Drenagem na bacia do Riacho Pioré, município de Ibimirim-PE. Revista Geonorte, Manaus, v. 10, n. 1, p. 251-255, 2014.

ROBAINA, L. E. S.; TRENTIN, R.; BAZZAN, T.; RECKZIEGEL, E. W.; VERDUM, R.; NARDIN, D. Compartimentação geomorfológica da bacia hidrográfica do Ibicuí, Rio Grande do Sul, Brasil: proposta de classificação. Revista Brasileira de Geomorfologia, v. 11, n. 2, p. 11-23, 2010.

ROSS, J. L. S. Análise Empírica da Fragilidade dos Ambientes Antropizados. Geography Department, University of São Paulo, São Paulo, p. 63-74, 1994. 
ROSS, J. L. S. O registro cartográfico dos fatos geomorfológicos e a questão da taxonomia do relevo. Revista do departamento de Geografia, v. 6, p. 17-29, 1992.

SAMPAIO, T. V. M.; AUGUSTIN, C. H. R. R. Índice de concentração da rugosidade: uma nova proposta metodológica para o mapeamento e quantificação da dissecação do relevo como subsídio a cartografia geomorfológica. Revista Brasileira de Geomorfologia, São Paulo, v. 15, n. 1, p. 47-60, 2014.

SIMON, L. H.; LUPINACCI, C. M. A cartografia geomorfológica como instrumento para o planejamento. 1. ed. Pelotas: Ed. UFPel, 2019. 172p.

SOUZA, D. V.; MARTINS, A. A.; FARIA, A. L. L. Aplicação do índice de Hack (sl) a um trecho do Rio Zêzere, Portugal. Revista Brasileira de Geomorfologia, São Paulo, v. 12, n. 1, p.23-28, 2011.

SOUZA, F. E. V.; FONSECA, B. M.; PIZANI, F. M. C. Compartimentação do relevo baseada em parâmetros morfométricos: uma proposta de índice global de dissecação do relevo. Os Desafios da Geografia Física na Fronteira do Conhecimento, Campinas, p.5513-5524. Instituto de Geociências - Unicamp, 2017.

SOUZA, F. E. V. Proposta de Compartimentação do Relevo baseada em parâmetros morfométricos.2014. 42 f. Monografia (Especialização) - Curso de Curso de Especialização em Geoprocessamento, Departamento de Cartografia, Universidade Federal de Minas Gerais, Belo Horizonte, 2014.

SPROL, C.; ROSS, J. L. S. Análise comparativa da fragilidade ambiental com aplicação de três modelos. GEOUSP: Espaço e Tempo, n. 15, p. 39-49, 2004. 